\title{
Space science projects may be grounded
}

[MUNICH] Leading European space scientists warned last week that Horizons 2000, the long-term science programme of the European Space Agency (ESA), could disintegrate unless a cap on its budget imposed by European governments two years ago is lifted in 1999.

The warning has come from the eight independent scientists who make up ESA's Space Science Advisory Committee (SSAC), and is based on a 'worst-case' scenario of what might happen if member states refuse to increase funding.

The decision to freeze the agency's science budget for three years was taken at ESA's last ministerial meeting in Toulouse in 1995. At that meeting, Europe's space ministers also agreed to consider extending the freeze to 2000 at their next scheduled meeting, which will probably be held in Bruges, Belgium, next June (see Nature 377, 667; 1995).

The loss of purchasing power resulting from the three-year freeze - estimated at 9 per cent - forced ESA to modify its Horizons 2000 programmes, which had been designed to run to 2009 , assuming an indexlinked budget to 2002 and an annual 5 per cent increase thereafter. The revised plan, whose concept was approved by ESA's Science Programme Committee in September, maintains the regular ECU650-million (US\$740-million) 'cornerstone' missions. But it abandons the ECU300-million medium-sized missions in favour of smaller, 'flexible' missions which can be planned at short notice and cost only ECU175 million, and low-cost technology-driven SMART missions (see Nature 389, 218; 1997).

According to this plan, four cornerstones, three SMART missions and seven flexible missions could be launched in the next 12 years. But the SSAC says it will not be possible to retain all these elements without resumption of a fully index-linked budget after 1999 and annual 5 per cent increases after 2002.

Last week, the committee put forward two new calculations based on worst-case scenarios. In the first - restoration of indexlinking, but failure to increase the budget after this - the cornerstone missions could be launched but the SMART missions would have to be abandoned.

In this scenario, the idea of flexible

\section{Millennium Moon mission seeks private funds}

[MUNICH] Plans being drawn up by the European Space Agency (ESA) to send a robotic expedition to the south pole of the Moon to celebrate the millennium have received a cool response from the agency's Space Science Advisory Committee (SSAC).

The Euromoon project was chosen from two 'millennium' ideas presented to ESA's council last December. The other idea the Star of Tolerance, a pair of orbiting balloons that would reflect sunlight back to Earth - was vetoed because of complaints that it would pollute the sky.

Euromoon was dreamed up by Wubbo Ockels, a former astronaut who now works at ESA's technology development centre, ESTEC, in the Netherlands. The mission would place a lander on the rim of the large Aitken crater at the lunar south pole.

The perpetual sunlight at that point - known as the Peak of Eternal Light - could

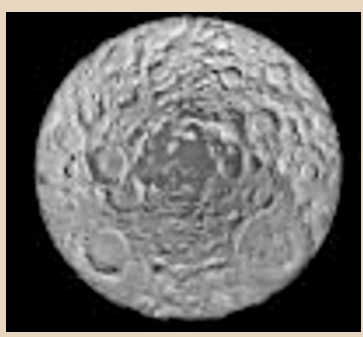

Bottom up: the lunar south pole, seen in a composite image.

provide constant solar power to the lander. Robots would gather samples from the crater, which is thought by some to contain ice.

The mission is ambitious, as a space vehicle would have to land with great precision on an area no larger than 100 metres square. Costs would be kept down to around ECU300 million (US\$342 million) by using off-the-shelf technologies and a small team of young scientists. The plan assumes support from ESA's own technological and operational facilities.

Euromoon, which is already registered as a trademark, must seek private sponsorship as ESA is unlikely to use its own funds. The SSAC was asked to help develop a science programme for the mission. But at a meeting last week the panel expressed concern about the burden it would place on its overstretched budget, and the fact that the mission has not passed through the standard peerreview processes.

The committee has asked its solar systems science working group for further advice. If the mission is to be launched in time for the astronomical millennium - which starts in 2001, rather than 2000 - Euromoon must secure financing quickly.

European space industries have indicated willingness to provide resources for the project. But a major bid has yet to be launched to persuade other industries to inject cash in return for vaguely defined commercial gains and advertising prospects. missions - based on the 'better, faster, cheaper' missions of the US National Aeronautics and Space Administration (NASA) - would, according to the SSAC, have to be abandoned, as their infrequency would produce insufficient data to keep the space science community alive. NASA scientists have also recently expressed doubts about the scientific value of 'lean missions' (see Nature 389, 899; 1997). So, instead of flexible missions, three medium-sized missions would be launched.

In the second scenario, which the SSAC refers to as the 'disaster scenario', the budget would remain capped at its 1999 level for the duration of the Horizons plan. If this were to happen, only three cornerstone missions and two medium-sized missions could be launched.

Both scenarios would mean delays to either the planned mission to Mars, Mars Express, or the infrared cornerstone FIRST mission, which is to be combined with the microwave background mission Planck.

Lodewijk Woltjer, outgoing chairman of the SSAC, says that, if the budget continues to decrease in real terms, "the Horizons 2000 programme will have to be effectively abandoned - Europe will just have to do the occasional mission".

ESA's Science Programme Committee will formally respond to the SSAC document this month. Informal responses indicate concern, and some delegations hope that their ministers will be persuaded to lift the freeze. Italy, the third largest contributor to ESA's budget, has made provision for this in its five-year space plan (see Nature 389, 651; 1997). But some countries, including Britain, Germany and Sweden, are likely to insist on a continuation of the budget freeze at the ministerial meeting next year.

Germany, the largest contributor to ESA, would like to support an increase, says Norbert Kiehne, director of the space programme of the German air and space agency DLR. But its hands are tied because there will be no increase in its overall space budget in the next few years, and priority is being given to commercial applications of space activities, according to a new government policy document.

Some believe there are other alternatives to the disaster scenario. Kiehne says that ESA should continue to improve its efficiency, to do more missions for less money. Paul Murdin of the Particle Physics and Astronomy Research Council, the UK delegate, agrees. The original estimates for the replacement for Cluster — the solar mission that was destroyed when the first Ariane 5 launch exploded last year — were more than halved when the Cluster team and ESA were put under pressure, he says.

Alison Abbott 